
\title{
25 Research Suare \\ Prdx1 Promotes the Loss of Primary Cilia in Esophageal Squamous Cell Carcinoma
}

\author{
Qiongzhen Chen \\ Wenzhou University \\ Jinmeng Li \\ Wenzhou Medical University \\ Xiaoning Yang \\ Wenzhou Medical University \\ Junfeng Ma \\ Wenzhou Medical University
}

Fanghua Gong ( $\sim$ gongwenheng@163.com )

Wenzhou Medical University https://orcid.org/0000-0002-8905-4894

Yu Liu

Wenzhou Medical University

\section{Research article}

Keywords: Prdx1; Cilia; ESCC; Invasion; Tumorigenesis

Posted Date: May 5th, 2020

DOI: https://doi.org/10.21203/rs.2.17849/v4

License: (ㅇ) (1) This work is licensed under a Creative Commons Attribution 4.0 International License. Read Full License

Version of Record: A version of this preprint was published at BMC Cancer on May 1st, 2020. See the published version at https://doi.org/10.1186/s12885-020-06898-y. 


\section{Abstract}

Background: Loss of primary cilia is frequently observed in tumor cells, suggesting that the absence of this organelle may promote tumorigenesis through aberrant signal transduction, the inability to exit the cell cycle, and promotion of tumor cell invasion. Primary cilia loss also occurs in esophageal squamous cell carcinoma (ESCC) cells, but the molecular mechanisms that explain how ESCC cells lose primary cilia remain poorly understood.

Methods: Inhibiting the expression of Prdx1 in the ESCC cells to detect the up-regulated genes related to cilium regeneration and down-regulated genes related to cilium disassembly by Gene chip. And, mice and cell experiments were carried to confirm the role of the HEF1-Aurora A-HDAC6 signaling axis in ESCC.

Results: In this study, we found that silencing Peroxiredoxin 1 (Prdx1) restores primary cilia formation, and overexpressing Prdx 1 induces primary cilia loss in ESCC cells. We also showed that the expression of Prdx 1 regulates the action of the HEF1-Aurora A-HDAC6 signaling axis to promote the disassembly of primary cilia, and suppression of Prdx1 results in decreased tumor formation and tumor mass volume in vivo.

Conclusions: These results suggest that $\operatorname{Prdx} 1$ is a novel regulator of primary cilia formation in ESCC cells.

\section{Background}

The primary cilium is an antenna-like organelle present on the surface of most types of mammals, with an extracellular signal transduction function that regulates cell growth and development. Cilium disassembly is closely associated with cell cycle progression and external signal transduction (1-3). Cilium disassembly occurs when cells proliferate and then restoration occurs once mitosis is complete (4). Structural or functional cilia anomalies are associated with many genetic diseases, which are collectively called ciliopathies $(5,6)$. Recent studies have shown that cilia are closely associated with tumorigenesis (7-9), and primary cilia are disassembled or lost in many tumor tissues, including esophageal squamous carcinoma (ESCC) $(3,10)$, colon cancer (11), breast cancer (12), hepatic carcinoma (13), cholangiocarcinoma (14), and thyroid cancer (15). This suggests that inhibition of cilia disassembly or loss in tumor cells or the promotion of ciliary regeneration may inhibit the proliferation and invasion of tumor cells.

ESCC is the major histological subtype of esophageal carcinoma. Recent studies have shown that 456,000 people are affected by esophageal carcinoma each year, of which esophageal squamous carcinoma accounts for about $90 \%(16,17)$. ESCC is one of the most aggressive tumors worldwide, with a five-year survival rate that is less than $20 \%(18,19)$. Prdx 1 is an antioxidant protein that is widely expressed in eukaryotic cells, protects cells from ROS damage (20), and regulates cell signal transduction by controlling cell proliferation and $\mathrm{H}_{2} \mathrm{O}_{2}$ activity. The abnormal expression of Prdx1 has been reported for many kinds of tumors $(21,22)$. Several studies have shown that Prdx1 is highly expressed in ESCC, and Prdx1 is closely related to the disassembly of primary cilia in tumors (23). Thus, Prdx1 and primary cilia may play an important role in the development of ESCC, making Prdx1 an exciting potential target for tumor treatment. However, the detailed molecular mechanism by which Prdx1 regulates cilia disassembly in ESCC remains unclear.

Our previous research demonstrated that the evolutionary conserved Prdx1 participates in the regulation of cilium disassembly, and decreases the activity of Aurora A, a marker protein of cilium disaggregation $(3,10)$. In this study, we expanded that work and found that inhibiting the expression of Prdx 1 in the ESCC cells 
significantly up-regulated genes related to cilium regeneration and down-regulated genes related to cilium disassembly. Cell and animal experiments were performed and demonstrated that Prdx 1 plays a regulatory role in the key signal axis of cilium disassembly, NEDD9 (HEF1)-Aurora A-HDAC6, and affects the tumorigenicity and invasiveness of ESCC cells. Overall, our results indicate that Prdx 1 contributes to disassembly of primary cilia by controlling the NEDD9-Aurora A-HDAC6 signal axis in ESCC.

\section{Methods}

\section{Cell strains and animals}

The human esophageal squamous carcinoma cell line EC9706 was obtained from the State Key Laboratory of Molecular Oncology, Chinese Academy of Medical Sciences. The experimental cells were divided into seven groups, normal EC9706 cells, EC9706 cells transfected with shPrdx1 lentivirus (shPrdx1), EC9706 cells transfected with negative control lentivirus (shControl), EC9706 cells transfected with OE-Prdx1 lentivirus (OEPrdx1), EC9706 cells transfected with corresponding negative control lentivirus (OE-Control), EC9706 cells treated with Tripolin A (EC9706+Tripolin A), and EC9706 cells transfected with OE-Prdx1 lentivirus and treated with Tripolin A (OE-Prdx $1+$ Tripolin A). Healthy male BALB/c nude mice (4 weeks, $n=20,10$ in each group) were provided by the Animal Center of the Chinese Academy of Science (Shanghai, China). All animals were raised and treated according to guidelines developed by the National Institutes of Health guide for the care and use of laboratory animals (NIH Publications No. 8023, revised 1978). The mice were housed under strictly controlled SPF environmental conditions and mice were sacrificed by $\mathrm{CO}_{2}$ inhalation.

\section{Acquisition of lentivirus}

The Prdx1 interfering and negative control lentivirus plasmid were constructed by inserting the target sequence (shPrdx1: TGTCTGACTACAAAGGAAA, shControl: TTCTCCGAACGTGTCACGT) into the Age I/EcoR I restriction enzyme cutting sites of the GV112-Lentivirus vector according to previous results (3). The over-express Prdx1 (Accession Number: NM_001202431) and control plasmid were constructed by inserting the target sequence into the Age I/BamHI restriction enzyme cutting sites of the GV287-Lentivirus vector. Plasmid vectors were obtained from the Genechem Co. Ltd (Shanghai, China). The synthesis of the target gene sequence, establishment of the plasmid carrier, and lentivirus packaging were performed as described previously. ${ }^{3}$

\section{Cell culture and lentivirus transfection}

The EC9706 cells were cultured in RPMI-1640 media (Gibco) containing 10\% fetal bovine serum (FBS, Gibco) in a humidified atmosphere of $5 \% \mathrm{CO}_{2}$ at $37{ }^{\circ} \mathrm{C}$. The $\mathrm{EC} 9706$ cells ( $\left.\mathrm{MOI}=100\right)$ were infected with shPrdx 1 lentivirus $\left(1 \times 10^{9} \mathrm{TU} / \mathrm{ml}\right)$ or the over-expressed Prdx 1 lentivirus $\left(1 \times 10^{8} \mathrm{TU} / \mathrm{ml}\right)$ to decrease or increase the levels of Prdx 1 . The corresponding negative control lentivirus was similarly transfected into cells. The procedure was as follows. EC9706 cells were inoculated into a 6 -well microplate at a density of $1 \times 10^{5} /$ well. Next, $1 \mathrm{ml}$ of culture medium without antibiotics was added to each well when the cells grew to $30 \%$ confluence. Then, $5 \mathrm{mg} / \mathrm{ml}$ polybrene and the lentivirus were added and cultured for $12 \mathrm{~h}$ at $37^{\circ} \mathrm{C}$, followed by the addition of $2 \mathrm{ml}$ of fresh culture medium. The expression of GFP fluorescent protein was measured as an indicator of the efficiency of lentivirus transfection using an inverted fluorescence microscope. The cells were collected at $72 \mathrm{~h}$ for further experiments.

\section{Gene chip detection}


Gene chip detection was used to detect the changes in gene and signal pathways in ESCC cells following Prdx1 interference. The total RNA of control EC9706 cells and cells in which Prdx1 was inhibited were isolated using the Trizol reagent. The extracted total RNA samples were subjected to quality testing with a NanoDrop 2000 and an Agilent Bioanalyzer 2100. The qualified samples were then applied to a human gene expression profile chip (chip type: GeneChip primeview human, number: 901838) developed by Affymetrix. The hybridization, washing of the gene chip, scanning, and data analysis were completed by the Genechem Co. Ltd (Shanghai, China).

\section{Tumor formation in nude mice}

Negative control EC9706 cells in logarithmic growth phase and EC9706 cells with inhibited levels of Prdx1 were prepared as cell suspensions and injected subcutaneously into the right axillary of nude mice $\left(2 \times 10^{7} / \mathrm{ml}, 200 \mu \mathrm{l}\right.$ for each). The body weight and tumor volume of each nude mouse were measured twice each week. Each nude mouse was sacrificed under anesthesia at $23 \mathrm{~d}$ and the mice were put into a live imaging device (IVIS ${ }^{\circledR}$ Lumina III) for luciferase luminescence detection, and the tumor was removed, weighed, photographed, and preserved after the mouse was sacrificed.

\section{Immunofluorescence detection of cell cilia}

In order to induce cell cilia formation, the cells were inoculated into a 24-well plate. When the cell density was $80 \%$, the culture medium was replaced by fresh serum-free medium for 4-6 d. To measure immunofluorescence, slides with cells were fixed with $4 \%$ polyformaldehyde for $30 \mathrm{~min}$, incubated with glycine $(2 \mathrm{mg} / \mathrm{ml})$ for $5 \mathrm{~min}$, and then blocked with 5\% BSA for 20 min. The rabbit anti-acetyl-a-Tubulin (1:500, Abcam) antibody was then added and incubated overnight at $4{ }^{\circ} \mathrm{C}$. After washing with PBST three times, the cells were then incubated with sheep anti-rabbit antibody (1:200, Santa Cruz), labeled with IgG/TR for $1 \mathrm{~h}$ at $37^{\circ} \mathrm{C}$, and then washed with PBST three times. Nucleus staining was performed by DAPI reagent for $7 \mathrm{~min}$ and then the cover slide was sealed. Positive fluorescence microscopy (ECLIPSE NI, Nikon, Japan) was used to observe and photograph cells.

\section{Quantitative real-time PCR}

cDNA was synthesized from total RNA $(1 \mu \mathrm{g})$ purifified using TRIzol reagent, and then quantitative real-time reverse transcription PCR (qRT-PCR) was performed on a Rotor-Gene 6000 thermocycler (Corbett Research, Sydney, Australia) using a KAPA SYBR FAST Universal 2X qRT-PCR Master Mix (Kapa Biosystems, Woburn, MA, USA) . The primers for FGFR1, IGF1R, ABI2 and NEDD9, Aurora A, HDAC6 were designed by Sangon Biotech (Shanghai, China). PCR reaction parameters were as follows: 1 cycle of $95^{\circ} \mathrm{C}$ for 3 min, followed by 40 cycles each comprising three steps of $95^{\circ} \mathrm{C}$ for $3 \mathrm{~s}, 55^{\circ} \mathrm{C}$ for $15 \mathrm{~s}$, and $72{ }^{\circ} \mathrm{C}$ for $30 \mathrm{~s}$. All PCR samples were prepared in triplicate and the relative mRNA expression levels were normalized to GAPDH and determined by the $2^{-\triangle \Delta C t}$ method.

\section{Transwell Invasion Experiment}

Transwell invasion chambers (article number: 354480, Corning) were used to detect cell invasion capacity. Serum-free medium was preheated at $37^{\circ} \mathrm{C}$, added to the upper chamber, and incubated in a $37{ }^{\circ} \mathrm{C}$ incubator for $2 \mathrm{~h}$. After discarding the medium, $500 \mu \mathrm{l}$ fresh medium containing 10\% FBS was added to the lower chamber and $300 \mu \mathrm{l}$ cell suspension $\left(2 \times 10^{5} \mathrm{cells} / \mathrm{ml}\right)$ was added to the upper chamber. After incubation for $24 \mathrm{~h}$, the chamber was removed, washed twice with PBS, and then fixed with $5 \%$ glutaraldehyde for 30 min at $4{ }^{\circ} \mathrm{C}$. The cells were 
stained with $1 \%$ crystal violet staining solution for 20 min and then washed three times with PBS. The cells on the upper surface were cleaned with cotton balls, and we photographed the cells in the under surface of the chamber using an inverted microscope (Nikon, Japan). The mean value was determined by averaging the number of cells counted in nine visual fields.

\section{Western-blot experiment}

Western-blotting was used to detect and analyze the levels of proteins in cells and tumor tissues. Total proteins were extracted from cells or tissues, quantified with the BCA reagent method, and then separated by $8 \%$ or $10 \%$ $(\mathrm{w} / \mathrm{v})$ SDS-PAGE. The protein was transferred to a PVDF membrane (Bio-Rad, Hercules), blocked for $1.5 \mathrm{~h}$ with $5 \%(\mathrm{w} / \mathrm{v})$ skim milk in TBST at room temperature, and incubated overnight at $4{ }^{\circ} \mathrm{C}$ with the Prdx 1 antibody (1:10000, Abcam), NEDD9 antibody (1:1000, Cell signaling technology), p-Aurora A antibody (1:1000, Gentex), Aurora A antibody (1:10000, Abcam), HDAC6 antibody (1:10000, Abcam), or the GAPDH antibody (1:10000, Abcam). The membranes were washed three times with TBST and then incubated with horseradish peroxidaseconjugated (HRP) secondary antibody for $1 \mathrm{~h}$ at room temperature. The protein signal was detected using a protein gel imaging system (ChemiDocXRS + Imaging System; Bio-Rad).

\section{Statistical analysis}

All data were expressed as the mean \pm SEM. A one-way analysis of variance and $t$ test were performed to compare the differences among various samples. All data were analyzed using the software GraphPad Prism 5.0. The difference was statistically significant if $\mathrm{P}<0.05$.

\section{Results}

\section{Inhibition of prdx1 restored primary cilia and suppressed tumor invasion}

In order to study the effect of inhibition of Prdx1 on cilia and cell function, we used gene chip detection followed by experiments in cells to verify the findings. A lentivirus (shPrdx1) was transfected into EC9706 cells to inhibit the expression of Prdx1. EC9706 cells transfected with shPrdx1 lentivirus and shControl lentivirus (negative control) were subjected to gene chip analysis to study the potential changes in gene expression and signal pathways of cells after inhibition of Prdx1.

The gene chip detection results showed that the Prdx1 gene level decreased (FC: -5.9895 , P-value: $1.04 \times 10^{-7}$ ) significantly in EC9706 cells transfected with the shPrdx1 lentivirus. There were 512 up-regulated genes and 340 down-regulated genes relative to the negative control group when Prdx1 was inhibited (Figure 1A and Table S1), using a screening standard specifying a significant difference in gene expression as a value of $|\mathrm{FC}|$ greater than 2 and a P-value less than 0.05 . We studied the relationship between the up-regulation and down-regulation of differentially expressed genes with the activation or inhibition of diseases and cell functions (Figure 1B, C). Genes related to the formation of cellular protrusions (cilia) were significantly activated, and genes influencing the invasion of tumor cells (cell movement of the carcinoma cell line) were significantly inhibited after the inhibition of Prdx1 (Table 1). The enrichment of differentially expressed genes in disease and cell functional classifications are presented in Table 1 and Table S2. We also studied the occurrence of significantly differentially expressed genes in the classical signaling pathway based on the public database and the results of gene detection, and the results are presented in Table S3 and Figure S1. In order to confirm the gene chip results, 
we used RT-PCR, and the results showed that the mRNA level of FGFR1, IGFR1, and ABI2 were significantly increased after the inhibition of Prdx1 (Figure S2A-D), and the mRNA level of NEDD9, Aurora A and HDAC6 were significantly decreased after the inhibition of $\operatorname{Prdx} 1$ (Figure S2E-G). Studies have shown that FGFR1 knockout can cause ciliary shortening $(24,25)$, IGFR1 plays an important role in ciliary elongation $(26,27)$, and ABI2 is a tumor suppressor and a cell migration suppressor, participating in human head and neck squamous cell carcinoma (28). And NEDD9 and Aurora A was also known as important oncogenes regulating, correspondingly, cell division and cell invasion (29-32). The changes in the mRNA levels of these genes suggest that Prdx1 may play an important role in the formation of cilia and the invasion of ESCC.

We also conducted a cell culture experiment to study the effect of Prdx1 on ESCC. The Prdx1 interference lentivirus (shPrdx1), the over-expressed Prdx1 (OE-Prdx1) lentivirus, and corresponding negative control lentivirus (shControl and OE-Control) were used to separately transfect EC9706 cells. The expression of Prdx1 was decreased compared with the level in the negative control group (shControl) after transfection with the shPrdx 1 lentivirus, and the expression of Prdx 1 was increased compared with the level in the negative control group (OEControl) after transfection with the OE-Prdx1 lentivirus (Figure 2A-C). To study the effect of Prdx1 on cilia, an immunofluorescence experiment was used to detect acetyl-a-tubulin, a cilium marker protein. The results showed that the amount of cells with cilia (\%) was increased by more than 2 -fold after Prdx 1 was inhibited, and in the OEPrdx 1 lentivirus group, the amount of cells with cilia (\%) was decreased by more than 3.1 -fold compared with the negative control group (Figure 2D, E). A Transwell invasion experiment was conducted to study the effect of Prdx 1 on the invasion of tumor cells, and the results showed that compared with the control group, there was a $30 \%$ decrease of tumor invasion capacity after Prdx 1 inhibition and a $32 \%$ increase of tumor invasion capacity after Prdx 1 was over-expressed (Figure 2F, G). The above results were consistent with the results of the gene chip detection, which indicated that the inhibition of Prdx 1 in the EC9706 cells could promote cilia regeneration and inhibit the invasion capacity of the tumor cells.

\section{Prdx1 regulated the expression of the cilium disassembly signal axis of NEDD9-Aurora A-HDAC6 in ESCC}

In previous work, we demonstrated that inhibition of Prdx1 in EC9706 cells could promote cilia regeneration and down-regulate the expression of the key cilium disassembly protein, Aurora A. Several studies have suggested that the scaffolding protein NEDD9 (HEF1) can activate the oncogenic Aurora A (AurA) kinase at the basal body of cilia, which in turn causes phosphorylation and activation of HDAC6, a tubulin deacetylase, promoting cilium disassembly (29-32). HDAC6 inhibition can enhance the efficacy of anticancer agents in cancers and suppress ESCC proliferation $(33,34)$. Thus, we speculated whether Prdx 1 could influence the expression of the cilia disassembly signal axis NEDD9-Aurora A-HDAC6. The gene chip and RT-PCR results indicated that the mRNA levels of NEDD9, Aurora A, and HDAC6 were significantly decreased in response to inhibition of Prdx1 (Figure S2D-F). Cells containing the shPrdx 1 lentivirus or negative control (shControl) lentivirus were tested and showed that the expression levels of NEDD9, p-Aurora A, and HDAC6 were significantly decreased in Prdx1-inhibited cells (Figure 3A, B). The OE-Prdx 1 lentivirus increased the expression of Prdx 1 , and the levels of NEDD9, p-Aurora A, and HDAC6 were also up-regulated when Prdx 1 was overexpressed (Figure 3C, D). These results showed that Prdx 1 regulated the expression of NEDD9, Aurora A, and HDAC6 in EC9706 cells, and suggest the promoting effect of Prdx1 on cilia disassembly and tumor invasion may be through regulation of the NEDD9-Aurora AHDAC6 signal axis.

\section{Tripolin A Reversed the Effects of Over-expressed Prdx1 on Cilium Disassembly and Tumor Invasion}

Page 6/22 
We found that Prdx1 could regulate the expression of NEDD9, Aurora A, and HDAC6 in ESCC, but the relationship between these expression effects in ESCC and whether the action of Prdx1 to promote cilium disassembly and tumor invasion were achieved through regulation of the NEDD9-Aurora A-HDAC6 signal axis were inconclusive. Thus, we next used the Aurora A inhibitor Tripolin A to inhibit the activity of Aurora A ( $p$-Aurora A), to investigate the relationship of Prdx1 with NEDD9-Aurora A-HDAC6 signal axis. We stimulated EC9706 cells with different concentrations of Tripolin A $(0,1.5,4.5,7.5$, or $10.5 \mu \mathrm{mol} / \mathrm{L})$ for $12 \mathrm{~h}$, and observed that the expression of $\mathrm{p}$ Aurora A decreased in a dose-dependent manner (Figure 4A, B). EC9706 cells were stimulated with $4.5 \mu \mathrm{mol} / \mathrm{L}$ Tripolin A for $0,2,4,8$, and $12 \mathrm{~h}$, and we observed that the expression of p-Aurora A gradually decreased (Figure $4 C, D)$. Based on these results, we stimulated EC9706 cells at a concentration of $4.5 \mu \mathrm{mol} / \mathrm{L}$ for $2 \mathrm{~h}$ and observed that the expression of Aurora A and HDAC6 decreased significantly (Figure 4E, F), suggesting that Aurora A could regulate the expression of HDAC6 in ESCC. Use of $4.5 \mu \mathrm{mol} / \mathrm{L}$ Tripolin A to stimulate cells for $2 \mathrm{~h}$ inhibited the activity of Aurora A ( $\mathrm{p}$-Aurora A) and blocked the NEDD9-Aurora A-HDAC6 signal axis. Under these conditions, over-expressed Prdx1 no longer enhanced the expression of HDAC6 (Figure 4G, H) and the effects of Prdx1 to promote cilia depolymerization (Figure 5A, B) and cell invasion (Figure 5C, D) weakened. Thus, the above results suggest that Prdx 1 could promote cilia disassembly and tumor invasion in ESCC, and these promoting effects on cilium disassembly and tumor invasion were mediated through the NEDD9-Aurora A-HDAC6 signal axis.

\section{Inhibition of Prdx1 decreased tumorigenesis, reduced tumor volume and weight, and promoted cilium regeneration}

We next conducted an animal experiment to test the effect of Prdx1 on tumorigenesis. We used EC9706 cells to induce tumor formation in mice, using immune-deficient nude mice as a transplant carrier to avoid xenogeneic exclusion $(35,36)$. Negative control EC9706 cells in logarithmic growth phase and EC9706 cells with inhibited Prdx1 levels were prepared as cell suspensions and injected subcutaneously into the right axillary of nude mice. Live imaging was used to detect the tumor formation capacity, and the radiant efficiency and distribution of luciferase luminescence were used as indicators of tumor formation ability and tumor invasive capacity, respectively. The results showed that the average radiant efficiency of luciferase luminescence was decreased 1.25-fold times when Prdx1 was inhibited, relative to the level in the negative control group. Additionally, the cells in which Prdx1 was inhibited also showed a decrease in the distribution of luciferase luminescence (Figure 6A, $B)$. These results suggest that Prdx1 inhibition significantly decreased both tumor formation ability and tumor invasive capacity. The mice tumor weight and volume also decreased significantly after inhibition of Prdx 1 (Figure 6C-E). We also removed the mice tumors and used immunofluorescence to detect the cilium marker protein Acetyl-a-tubulin. The results showed that the formation of tumor cell cilia was significantly increased following Prdx1 inhibition compared with this process in the control group (Figure 6F, G). The above result suggests that Prdx1 can promote the occurrence and progression of esophageal squamous carcinoma by inducing cilia disaggregation. The inhibition of Prdx1 expression promoted cilia regeneration and inhibited the invasion of tumor cells.

\section{Decreased Prdx1 down-regulated the cilium disaggregation signal axis NEDD9-Aurora A-HDAC6 in tumor tissue}

We further analyzed the intracellular proteins of animal tumors in nude mice. The expression of Prdx 1 was decreased in the shPrdx1 group compared with the level in the negative control group. Additionally, the expression levels of intracellular NEDD9, p-Aurora A, and HDAC6 were also significantly decreased in the shPrdx1 group (Figure 7). This was consistent with the above cellular assay results, and further indicated that the action 
of Prdx1 to promote carcinoma cilium disaggregation and tumor invasion in esophageal squamous cells was achieved by modulation of the NEDD9-Aurora A-HDAC6 signal axis.

\section{Discussion}

Prdx 1 is a member of the peroxide oxidation-reduction enzyme family, and its abnormal expression is closely associated with multiple types of tumors (37-39). Recent studies indicated that the high expression of Prdx1 can promote the occurrence and progression of esophageal carcinoma and that inhibition of Prdx 1 expression can promote radiation and chemotherapy sensitivity for esophageal carcinoma treatment $(40,41)$. We previously found that Prdx1 can promote cilia disaggregation in ESCC and strengthen the invasion capacity of tumor cells. Additionally, the inhibition of Prdx1 expression can promote cilium regeneration and down-regulate the activity of the cilium disaggregation marker protein Aurora A $(3,10)$. Here, inhibition of the expression of Prdx 1 in ESCC cells significantly up-regulated genes related to cilium regeneration and down-regulated genes related to cilium disaggregation. Cell and animal experiments demonstrated that Prdx 1 plays a role in regulation of the critical NEDD9-Aurora A-HDAC6 signal axis of cilium disaggregation and influences the tumor formation and invasion capacity of ESCC cells. These results showed that Prdx1 was a critical regulator of cilium disaggregation in ESCC, making it an important target for treatment.

Inhibiting Prdx1 expression with the shPrdx1 lentivirus promoted cilia formation in EC9706 cells and inhibited the invasion capacity of the tumor cells. In nude mice, the tumor formation capacity, the tumor volume, and tumor weight were significantly decreased after inhibition of Prdx1. Thus, Prdx1 can promote the occurrence and progression of ESCC by inducing cilia disaggregation. Our results are consistent with other findings that inhibition of Prdx1 can inhibit the occurrence, invasion, and metastasis of tumors $(42,43)$. However, multiple mechanisms have been proposed to explain Prdx1's effects on cilia depolymerization. Chae Soomin et al (44) found that Prdx1 knockdown markedly inhibited proximal tubule formation in the pronephros during embryogenesis, significantly increased the cellular levels of reactive oxygen species (ROS), and impaired primary cilia formation, findings that do not agree with our observations. The difference in activities may reflect different roles of Prdx1 in cilia formation for different cellular components and different disease conditions. Additional experiments are warranted to expand these experiments to characterize the effect of Prdx 1 on cilia.

Previous research showed that the inhibition of Prdx1 can down-regulate the expression of Aurora A, a key protein in cilium disaggregation. ${ }^{3,10}$ Recent research has also shown that the NEDD9-Aurora A-HDAC6 signal axis plays an important role in this process $(45,46)$. Based on our results, we propose that the action of Prdx 1 on cilium disaggregation may be achieved through modulation of the NEDD9-Aurora A-HDAC6 signal axis. Our results showed significantly decreased expression of NEDD9, Aurora A, and HDAC6 when Prdx1 was inhibited with the shPrdx1 lentivirus. The expression of NEDD9, Aurora A, and HDAC6 also increased significantly when Prdx 1 was over-expressed under the action of the OE-Prdx1 lentivirus. Stimulating the ESCC cells with the Aurora A inhibitor Tripolin A reversed the effect of the over-expressed Prdx1 on p-Aurora A and HDAC6 proteins, and decreased $\mathrm{p}$-Aurora A enhancement of cilium regeneration and inhibited the invasion of tumor cells. Therefore, the effects of Prdx1 to strengthen the cilium disaggregation and invasion capacity of ESCC cells were mediated through regulation of the NEDD9-Aurora A-HDAC6 signal axis. Both Prdx1 and the NEDD9-Aurora A-HDAC6 signal axis play important roles in the occurrence and progression of ESCC, making both factors potential targets for treatment. 
Several studies have showed that Prdx1 promotes tumor occurrence mainly by adjusting the levels of ROS, TGFß1, mTOR/p70S6K, and ROS/ERK/cyclin D1 (47-49). However, the effect and mechanism of Prdx1 on esophageal squamous cell carcinoma still need to be further explored. Here, we demonstrated that the NEDD9Aurora A-HDAC6 signal pathway plays an important role in cilium disaggregation and tumor invasion. The results from the animal and cell culture experiments demonstrated that the signal axis mediates the role of Prdx 1 to promote the occurrence and progression of cilium disaggregation and ESCC. There may be additional molecular mechanisms through which Prdx1 can influence the occurrence and progression of ESCC. Additionally, the applicability of the observed effects of Prdx1 on the NEDD9-Aurora A-HDAC6 signal axis to other tumor aspects requires future study.

\section{Conclusions}

Our results suggest that $\operatorname{Prdx} 1$ is a novel regulator of primary cilia formation in ESCC cells.

\section{Abbreviations}

Prdx1: Peroxiredoxin 1; ESCC: esophageal squamous cell carcinoma; HEF1: human enhancer of filamentation 1; HDAC6: Histone Deacetylase 6.

\section{Declarations}

Ethics approval and consent to participate: This study was carried out in accordance with the principles of the Basel Declaration and recommendations of [Laboratory animal-Guideline for ethical review of animal welfare], [Laboratory Animal Ethics Committee of Wenzhou Medical University]. The protocol was approved by the [Laboratory Animal Centre of Wenzhou Medical University].

Consent for publication: Not applicable.

Availability of data and material: All data generated or analysed during this study are included in this published article [and its supplementary information files].

Competing interests: The authors declare that they have no competing interests.

Funding: This research was supported by the Zhejiang Provincial Natural Science Foundation of China under grant LY17H160048 and LQ16H160021. The funding body had no involvement in the design of the study, collection, analysis, and interpretation of data and in writing the manuscript.

Authors' contributions: CQJ, LJM, YXN, and MJF carried out most of the experimental work; CQJ and LJM analyzed the data; GFH and LY supervised the project and wrote the manuscript. All authors read and approved the final manuscript. CQZ and LJM contributed equally to this work.

Acknowledgements: Not applicable.

\section{References}


1. Kobayashi T, Nakazono K, Tokuda M, Mashima Y, Dynlacht BD, Itoh H: HDAC2 promotes loss of primary cilia in pancreatic ductal adenocarcinoma. EMBO Rep 18: 334-343, 2017.

2. Sánchez I, Dynlacht BD: Cilium assembly and disassembly. Nat Cell Biol 18: 711-717, 2016.

3. Gong F, Liu H, Li J, Xue L, Zhang M: Peroxiredoxin 1 is involved in disassembly of flagella and cilia. Biochem Biophys Res Commun 444: 420-426, 2014.

4. Goto $\mathrm{H}$, Inoko A, Inagaki M: Cell cycle progression by the repression of primary cilia formation in proliferating cells. Cell Mol Life Sci 70: 3893-3905, 2013.

5. Toomer KA, Fulmer D, Guo L, Drohan A, Peterson N, Swanson P, Brooks B, Mukherjee R, Body S, Lipschutz JH, et al: A role for primary cilia in aortic valve development and disease. Dev Dyn 246: 625-634, 2017.

6. Thorpe SD, Gambassi S, Thompson CL, Chandrakumar C, Santucci A, Knight MM: Reduced primary cilia length and altered Arl13b expression are associated with deregulated chondrocyte Hedgehog signaling in alkaptonuria. J Cell Physiol 232: 2407-2417, 2017.

7. Eberhart C: Multiple cilia suppress tumour formation. Nat Cell Biol 18: 368-369, 2016.

8. Yasar B, Linton K, Slater C, Byers R: Primary cilia are increased in number and demonstrate structural abnormalities in human cancer. J Clin Pathol 70: 571-574, 2017.

9. Jenks AD, Vyse S, Wong JP, Kostaras E, Keller D, Burgoyne T, Shoemark A, Tsalikis A, de la Roche M, Michaelis $\mathrm{M}$, et al: Primary cilia mediate diverse kinase inhibitor resistance mechanisms in cancer. Cell Rep 23: 3042-3055, 2018.

10. Gong F, Hou G, Liu H, Zhang M: Peroxiredoxin 1 promotes tumorigenesis through regulating the activity of mTOR/p70S6K pathway in esophageal squamous cell carcinoma. Med Oncol 32: 455, 2015.

11. Rocha C, Papon L, Cacheux W, Marques Sousa P, Lascano V, Tort O, Giordano T, Vacher S, Lemmers B, Mariani $\mathrm{P}$, et al: Tubulin glycylases are required for primary cilia, control of cell proliferation and tumor development in colon. EMBO J 33: 2247-2260, 2014.

12. Hassounah NB, Nunez M, Fordyce C, Roe D, Nagle R, McDermott KM: Inhibition of ciliogenesis promotes Hedgehog signaling, tumorigenesis, and metastasis in breast cancer. Mol Cancer Res 15: 1421-1430, 2017.

13. Han B, Shin HJ, Bak IS, Bak Y, Jeong YL, Kwon T, Park YH, Sun HN, Kim CH, Yu DY: Peroxiredoxin I is important for cancer-cell survival in Ras-induced hepatic tumorigenesis. Oncotarget 7: 68044-68056, 2016.

14. Mansini AP, Lorenzo Pisarello MJ, Thelen KM, Cruz-Reyes M, Peixoto E, Jin S, Howard BN, Trussoni CE, Gajdos GB, LaRusso NF, et al: MicroRNA (miR)-433 and miR-22 dysregulations induce histonedeacetylase-6 overexpression and ciliary loss in cholangiocarcinoma. Hepatology,

15. Lee J, Yi S, Won M, Song YS, Yi HS, Park YJ, Park KC, Kim JT, Chang JY, Lee MJ, et al: Loss-of-function of IFT88 determines metabolic phenotypes in thyroid cancer. Oncogene,

16. Abnet CC, Arnold M, Wei WQ: Epidemiology of Esophageal Squamous Cell Carcinoma. Gastroenterology 154: 360-373, 2018.

17. Ohashi S, Miyamoto S, Kikuchi O, Goto T, Amanuma Y, Muto M: Recent advances from basic and clinical studies of esophageal squamous cell carcinoma. Gastroenterology 149: 1700-1715, 2015.

18. Rustgi Anil K, El-Serag, Hashem B: Esophageal carcinoma. N Engl J Med 371: 2499-2509, 2014.

19. Murphy G, McCormack V, Abedi-Ardekani B, Arnold M, Camargo MC, Dar NA, Dawsey SM, Etemadi A, Fitzgerald RC, Fleischer DE, et al: International cancer seminars: a focus on esophageal squamous cell carcinoma. Ann Oncol 28: 2086-2093, 2017.

Page 10/22 
20. Chattopadhyay A, Pinkaew D, Doan HQ, Jacob RB, Verma SK, Friedman H, Peterson AC, KuyumcuMartinez MN, McDougal OM, Fujise K: Fortilin potentiates the peroxidase activity of Peroxiredoxin-1 and protects against alcohol-induced liver damage in mice. Sci Rep 6: 18701, 2016.

21. Ledgerwood EC, Marshall JW, Weijman JF: The role of peroxiredoxin 1 in redox sensing and transducing. Arch Biochem Biophys 617: 60-67, 2017.

22. Cai CY, Zhai LL, Wu Y, Tang ZG: Expression and clinical value of peroxiredoxin-1 in patients with pancreatic cancer. Eur J Surg Oncol 41: 228-235, 2015.

23. Ding C, Fan X, Wu G: Peroxiredoxin 1 - an antioxidant enzyme in cancer. J Cell Mol Med 21: 193-202, 2017.

24. Neugebauer JM, Amack JD, Peterson AG, Bisgrove BW, Yost HJ: FGF signalling during embryo development regulates cilia length in diverse epithelia. Nature 458: 651-654, 2009.

25. García-González D, Murcia-Belmonte V, Esteban PF, Ortega F, Díaz D, Sánchez-Vera I, Lebrón-Galán R, Escobar-Castañondo L, Martínez-Millán L, Weruaga E, et al: Anosmin-1 over-expression increases adult neurogenesis in the subventricular zone and neuroblast migration to the olfactory bulb. Brain Struct Funct 221: 239-260, 2016.

26. Dalbay MT, Thorpe SD, Connelly JT, Chapple JP, Knight MM: Adipogenic Differentiation of hMSCs is Mediated by Recruitment of IGF-1r Onto the Primary Cilium Associated With Cilia Elongation. Stem Cells 33 : 1952-1961, 2015.

27. Yeh C, Li A, Chuang JZ, Saito M, Cáceres A, Sung CH: IGF-1 activates a cilium-localized noncanonical GßY signaling pathway that regulates cell-cycle progression. Dev Cell 26: 358-368, 2013.

28. Kano S, Miyajima N, Fukuda S, Hatakeyama S: Tripartite motif protein 32 facilitates cell growth and migration via degradation of Abl-interactor 2. Cancer Res 68: 5572-5580, 2008.

29. Pugacheva EN, Jablonski SA, Hartman TR, Henske EP, Golemis EA: HEF1-dependent Aurora A activation induces disassembly of the primary cilium. Cell 129: 1351-1363, 2007.

30. Plotnikova OV, Nikonova AS, Loskutov YV, Kozyulina PY, Pugacheva EN, Golemis EA: Calmodulin activation of Aurora-A kinase (AURKA) is required during ciliary disassembly and in mitosis. Mol Biol Cell 23: 26582670, 2012.

31. Ran J, Yang Y, Li D, Liu M, Zhou J. Deacetylation of a-tubulin and cortactin is required for HDAC6 to trigger ciliary disassembly: Sci Rep 5: 12917, 2015.

32. Plotnikova OV, Seo S, Cottle DL, Conduit S, Hakim S, Dyson JM, Mitchell CA, Smyth IM: INPP5E interacts with AURKA, linking phosphoinositide signaling to primary cilium stability. J Cell Sci 128: 364-372, 2015.

33. Won HR, Ryu HW, Shin DH, Yeon SK, Lee DH, Kwon SH: A452, an HDAC6-selective inhibitor, synergistically enhances the anticancer activity of chemotherapeutic agents in colorectal cancer cells. Mol Carcinog,

34. Tao H, Chen YY, Sun ZW, Chen HL, Chen M: Silence of HDAC6 suppressed esophageal squamous cell carcinoma proliferation and migration by disrupting chaperone function of HSP90. J Cell Biochem 119: 6623-6632, 2008.

35. Fan T, Chen J, Zhang L, Gao P, Hui Y, Xu P, Zhang X, Liu H: Bit1 knockdown contributes to growth suppression as well as the decreases of migration and invasion abilities in esophageal squamous cell carcinoma via suppressing FAK-paxillin pathway. Mol Cancer 15: 23, 2016.

36. Shi HY, Lv FJ, Zhu ST, Wang QG, Zhang ST: Dual inhibition of 5-LOX and COX-2 suppresses esophageal squamous cell carcinoma. Cancer Lett 309: 19-26, 2011. 
37. O'Leary PC, Terrile M, Bajor M, Gaj P, Hennessy BT, Mills GB, Zagozdzon A, O'Conn DP, Brennan DJ, Connor K, et al: Peroxiredoxin-1 protects estrogen receptor a from oxidative stress-induced suppression and is a protein biomarker of favorable prognosis in breast cancer. Breast Cancer Res 16: R79, 2014.

38. Sun YL, Cai JQ, Liu F, Bi XY, Zhou LP, Zhao XH: Aberrant expression of peroxiredoxin 1 and its clinical implications in liver cancer. World J Gastroentero 21: 10840-10852, 2015.

39. Niu W, Zhang M, Chen H, Wang C, Shi N, Jing X, Ge L, Chen T, Tang X: Peroxiredoxin 1 promotes invasion and migration by regulating epithelial-to-mesenchymal transition during oral carcinogenesis. Oncotarget7: 47042-47051, 2016.

40. Ren P, Ye H, Dai L, Liu M, Liu X, Chai Y, Shao Q, Li Y, Lei N, Peng B, et al: Peroxiredoxin 1 is a tumorassociated antigen in esophageal squamous cell carcinoma. Oncol Rep 30: 2297-3303, 2013.

41. Qi Y, Chiu JF, Wang L, Kwong DL, He QY: Comparative proteomic analysis of esophageal squamous cell carcinoma. Proteomics 5: 2960-2971, 2005.

42. Zheng MJ, Wang J, Wang HM, Gao LL, Li X, Zhang WC, Gou R, Guo Q, Nie X, Liu JJ, et al: Decreased expression of peroxiredoxin 1 inhibits proliferation, invasion, and metastasis of ovarian cancer cell. Onco Targets Ther 11: 7745-7761, 2018.

43. Chen H, Wang C, Qi M, Ge L, Tian Z, Li J, Zhang M, Wang M, Huang L, Tang X: Anti-tumor Effect of Ethyl Acetate Extract by Regulation of Peroxiredoxin1 and Epithelial-to-Mesenchymal Transition in Oral Cancer. Front Pharmacol 8: 870, 2017.

44. Chae S, Lee HK, Kim YK, Jung Sim H, Ji Y, Kim C, Ismail T, Park JW, Kwon OS, Kang BS, et al: Peroxiredoxin1, a novel regulator of pronephros development, influences retinoic acid and Wnt signaling by controlling ROS levels. Sci Rep 7: 8874, 2017.

45. Xu J, Li H, Wang B, Xu Y, Yang J, Zhang X, Harten SK, Shukla D, Maxwell PH, Pei D, et al: VHL inactivation induces HEF1 and Aurora kinase A. J Am Soc Nephrol 21: 2041-2046, 2010.

46. Xia D, Holla VR, Wang D, Menter DG, DuBois RN: HEF1 is a crucial mediator of the proliferative effects of prostaglandin E(2) on colon cancer cells. Cancer Res 70: 824-831, 2010.

47. Chang JW, Lee SH, Jeong JY, Chae HZ, Kim YC, Park ZY, Yoo YJ: Peroxiredoxin-I is an autoimmunogenic tumor antigen in non-small cell lung cancer. FEBS Lett 579: 2873-2877, 2005.

48. Ha B, Kim EK, Kim JH, Lee HN, Lee KO, Lee SY, Jang HH: Human peroxiredoxin 1 modulates TGF- $\beta 1$-induced epithelial-mesenchymal transition through its peroxidase activity. Biochem Biophys Res Commun 421: 33$37,2012$.

49. Park YH, Kim SU, Lee BK, Kim HS, Song IS, Shin HJ, Han YH, Chang KT, Kim JM, Lee DS, et al: Prx I suppresses K-ras-driven lung tumorigenesis by opposing redox-sensitive ERK/cyclin D1 pathway. Antioxid Redox Signal 19: 482-496, 2013.

\section{Table 1}

Table 1 Effects of differentially expressed genes on disease and cell function after Prdx1 inhibition 


\begin{tabular}{|c|c|c|c|}
\hline Diseases or Functions Annotation & $\begin{array}{l}\text { Activation z- } \\
\text { score }\end{array}$ & p-Value & $\begin{array}{c}\text { Differentially expressed } \\
\text { genes (n) }\end{array}$ \\
\hline Tumorigenesis of tissue & -0.137 & $4.02 \mathrm{E}-13$ & 656 \\
\hline Proliferation of tumor cells & 0.927 & $1.52 \mathrm{E}-10$ & 56 \\
\hline Proliferation of cells & -0.89 & $5.22 \mathrm{E}-10$ & 269 \\
\hline Migration of tumor cell lines & -0.848 & $1.62 \mathrm{E}-09$ & 76 \\
\hline Cell proliferation of tumor cell lines & -0.281 & 7.1E-09 & 134 \\
\hline Microtubule dynamics & 1.768 & $1.43 \mathrm{E}-08$ & 106 \\
\hline Apoptosis of tumor cell lines & 1.059 & $1.62 \mathrm{E}-08$ & 108 \\
\hline Invasion of cells & -0.289 & $5.28 \mathrm{E}-08$ & 82 \\
\hline Cell death of tumor cell lines & 1.059 & 5.87E-08 & 127 \\
\hline Formation of cellular protrusions & 2.545 & 0.00000043 & 82 \\
\hline Cell movement of carcinoma cell lines & -2.11 & 0.00000964 & 25 \\
\hline Migration of carcinoma cell lines & -2.082 & 0.0000125 & 22 \\
\hline Invasion of tumor cell lines & -0.362 & 0.000000636 & 64 \\
\hline Attachment of cells & 2.187 & 0.000382 & 15 \\
\hline Engulfment of tumor cell lines & -1.75 & 0.000264 & 16 \\
\hline Gastrointestinal tract cancer & -0.926 & 0.000329 & 491 \\
\hline Extension of neurites & 1.946 & 0.000335 & 18 \\
\hline Migration of pancreatic cancer cell & -1.912 & 0.000338 & 8 \\
\hline \multicolumn{4}{|l|}{ lines } \\
\hline Development of kidney cell lines & -1.118 & 0.000369 & 7 \\
\hline Cell proliferation of kidney cell lines & -1.154 & 0.000426 & 18 \\
\hline Colony formation of lung cancer cell & -1.153 & 0.000448 & 8 \\
\hline lines & & & \\
\hline
\end{tabular}




\begin{tabular}{lccc} 
Invasion of digestive organ tumor & -1 & 0.000512 & 8 \\
\hline Invasion of epithelial cell lines & -1.577 & 0.000598 & 7 \\
\hline $\begin{array}{l}\text { Metastatic potential of tumor cell } \\
\text { lines }\end{array}$ & -1.404 & 0.000738 & 6 \\
\hline Extension of cellular protrusions & 1.257 & 0.00075 & 20 \\
\hline $\begin{array}{l}\text { Apoptosis of colorectal cancer cell } \\
\text { lines }\end{array}$ & 1.064 & 0.000782 & 22 \\
\hline Degeneration of nervous system & -2.101 & 0.000892 & 26 \\
\hline $\begin{array}{l}\text { Migration of prostate cancer cell } \\
\text { lines }\end{array}$ & -1.087 & 0.000924 & 12 \\
\hline Degeneration of neurons & -1.153 & 0.00133 & 22 \\
\hline Neurodegeneration & -1.99 & 0.00136 & 27 \\
\hline
\end{tabular}

Z-score $>2$ signifies that the function is significantly activated. Z-score $<-2$ signifies that the function is significantly inhibited. All diseases and functions are sorted using -Log (P-value), ranking from high to the bottom according to the value of -log ( $\mathrm{p}$-value)

\section{Supplementary File Legends}

Table S1 Changes in the expression of different genes after Prdx1 inhibition in EC9706 cells.

Intracellular differentially expressed genes after Prdx 1 inhibition are presented in Table S1. The screening standard for a significant difference in gene expression was a value of $|\mathrm{FC}|$ greater than 1.3 and a P-value less than 0.05 . Chip probe number and the FC information of the probe (Fold Change, the ratio of the expression of the treatment group to the control group) are listed.

Table S2 Differentially expressed genes in disease and cell functional classifications after Prdx 1 inhibition in EC9706 cells.

All diseases and cell functions were sorted using -Log (P-value) and are ranked from high to low according to the value of $-\log (p-v a l u e)$, indicating the relationships between differentially expressed genes and the activation or inhibition of the disease and cell function.

\section{Table S3 The occurrence of differentially expressed genes in classical signaling pathways.}


We studied the occurrence of significantly differentiated genes in classical signaling pathways based on data from public databases and the results of gene detection. We provide an enrichment analysis of the list of differentially expressed genes and the set of genes in the various classical pathways. We calculated the significance of $P$-value to determine which pathways of differentially expressed genes are enriched, as indicated in the classical pathway analysis column. A Z-score is given to indicate which pathways are activated or suppressed, based on the up/down regulation of genes according to chip analysis and the literature.

\section{Figure S1 Differentially expressed genes in classical signaling pathways.}

The signal pathway histogram shows the enrichment of differentially expressed genes in classical signaling pathways. All signal pathways are sorted using -Log (P-value). A larger -Log (P-value) indicated a more significant the enrichment of the pathway in the experimental results, and suggests a greater contribution of the pathway under that experimental condition. The orange marked signal pathways in the picture represents Zscore $>0$, while the blue marked signal pathway indicates $Z$-score $<0$. The Z-score shows the extent of activation or inhibition of the pathway under the experimental condition. The Z-score 2 represents significant activation of the pathway, and the Z-score<-2 represents significant inhibition of the pathway. The ratio represents the ratio of the number of differentially expressed genes to all the genes in the signal pathway.

Figure S2. Detection of mRNA levels of downstream factors after Prdx1 inhibition.

A-D Quantitative RT-PCR analysis was used to determine the relative mRNA level of Prdx1, FGFR1, IGFR1, and $A B I 2$. E-G Quantitative RT-PCR analysis was used to determine the relative mRNA level of NEDD9, Aurora A, and HDAC6. GAPDH was used as a loading control. All experiments were performed in triplicate and the results are expressed as mean \pm SEM. ${ }^{*} \mathrm{P}<0.05,{ }^{*} \mathrm{P}<0.01,{ }^{* \star *} \mathrm{P}<0.001$.

\section{Figures}


A
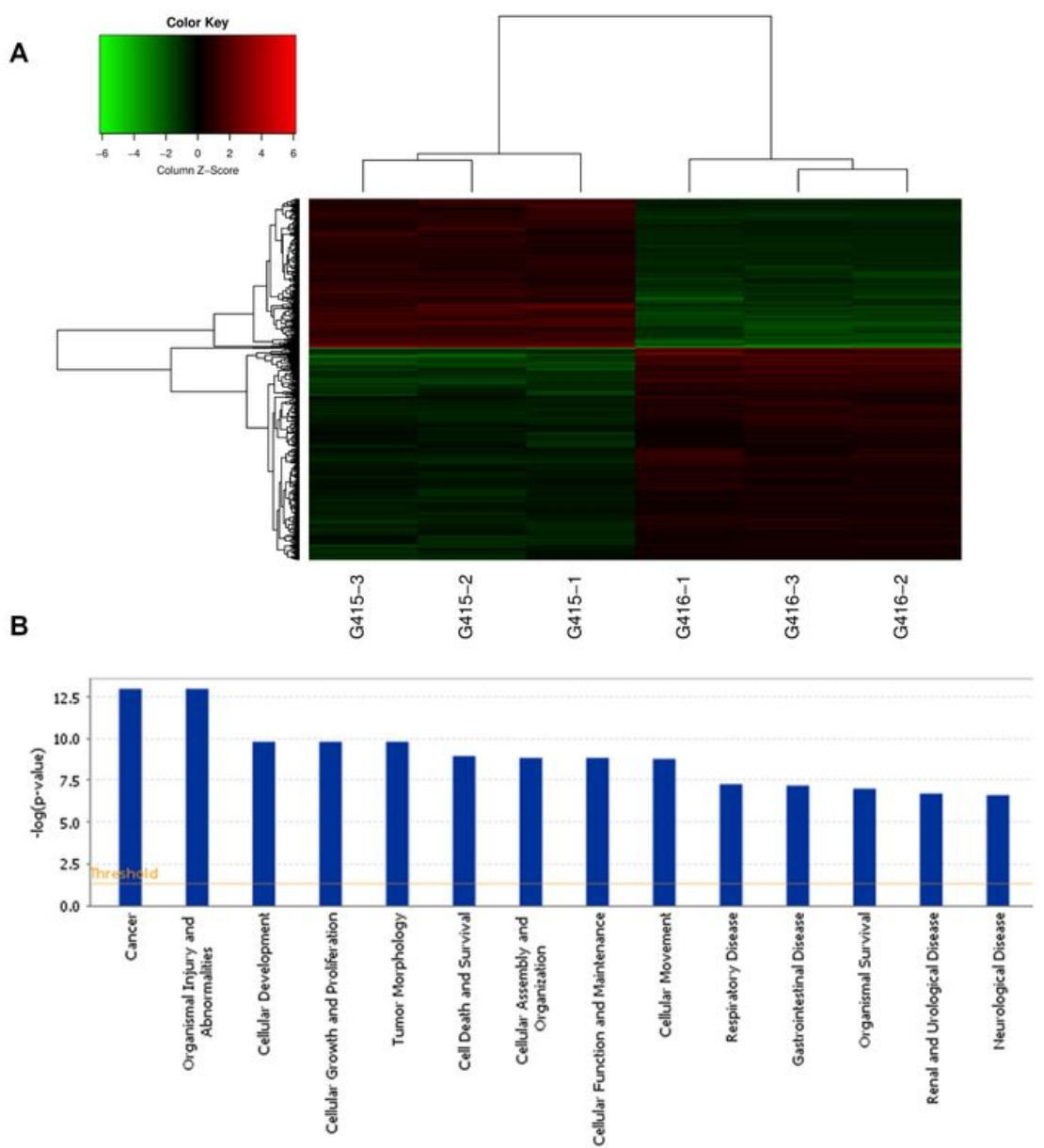

C

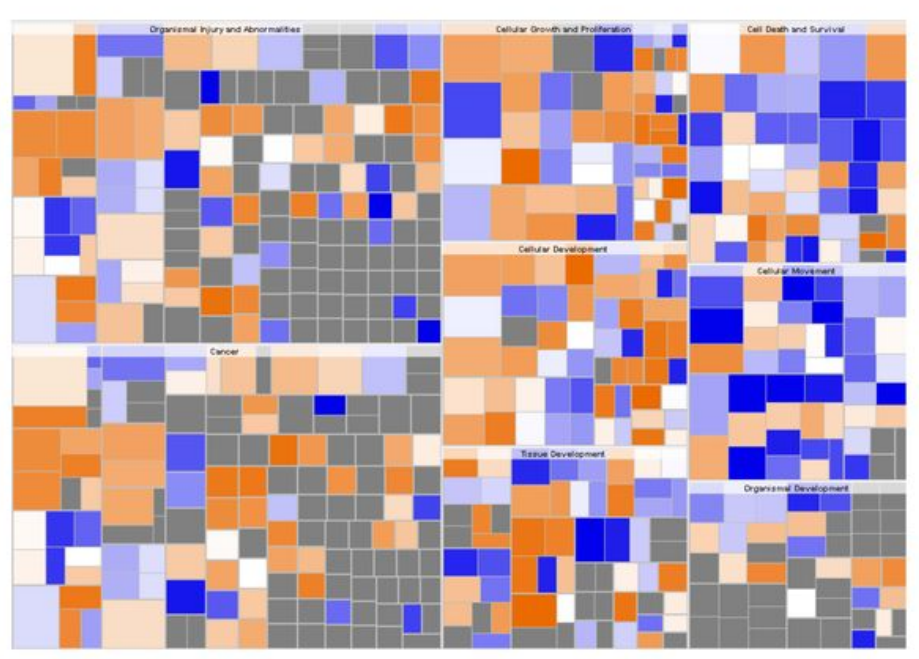

Figure 1

Gene chip detection after Prdx1 inhibition. A Changes of relevant genes in cells after inhibition of Prdx1. Negative control group: G415-1, G415-2, and G415-3. shPrdx1 group: G416-1, G416-2, and G416-3. The screening standard for a significant difference in gene expression was a value of $|\mathrm{FC}|$ greater than 1.3 and a P-value less than 0.05 . Red signifies that the signal value of the gene is relatively up-regulated. Green signifies that the signal value of the gene is relatively down-regulated. Black signifies a moderate signal value of the gene. Grey signifies that no signal value was detected. B Differentially expressed genes in disease and cell functional classifications after Prdx1 inhibition in EC9706 cells. All diseases and cell functions were sequenced with -Log (P-value). C The effects of differentially expressed genes on cell function and diseases after Prdx 1 inhibition. Orange signifies Z- 
score $>0$. Blue signifies Z-score $<0$. Grey signifies no Z-score value. Z-score $>2$ signifies that the function is significantly activated. Z-score<-2 signifies that the function is significantly inhibited.
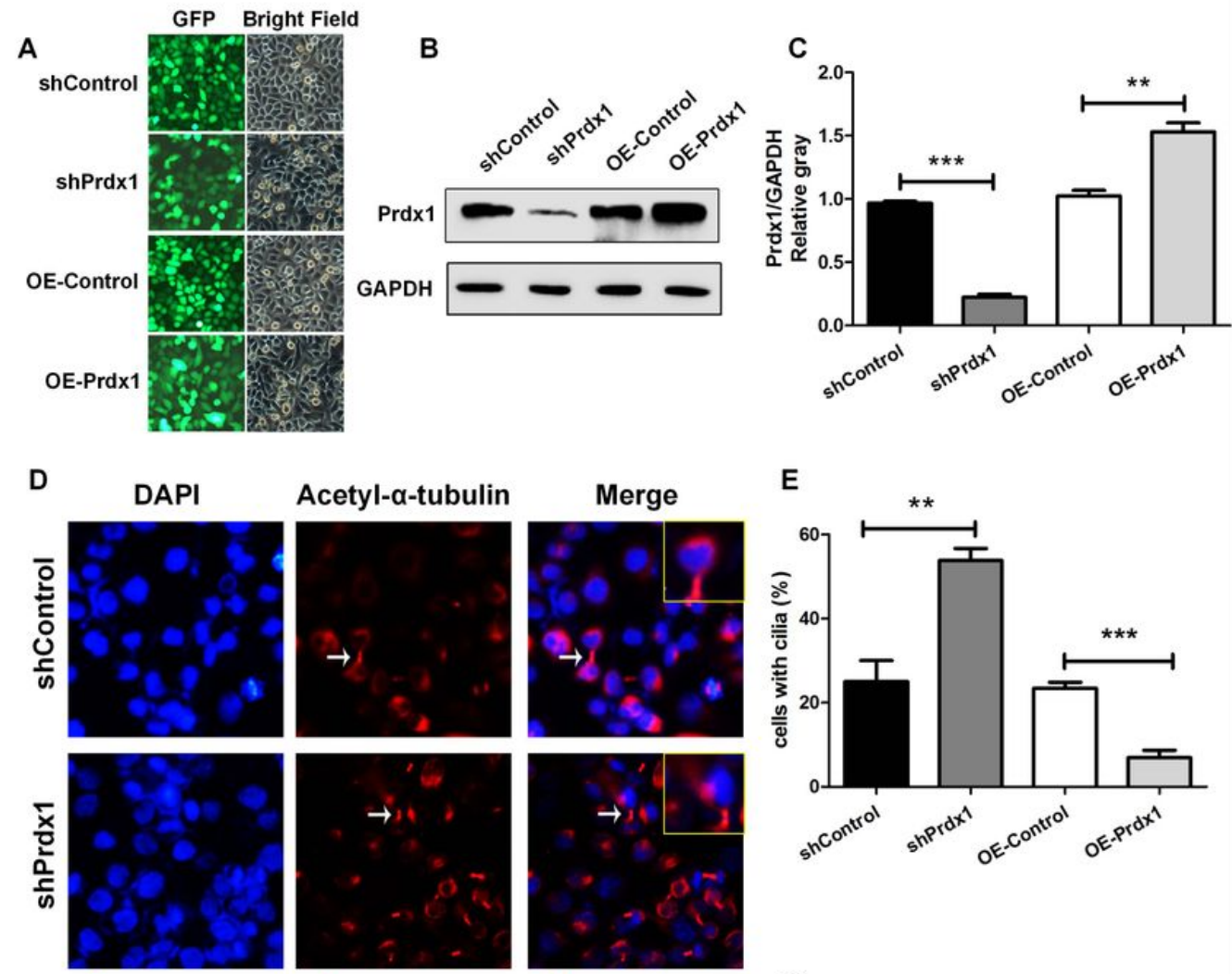

E
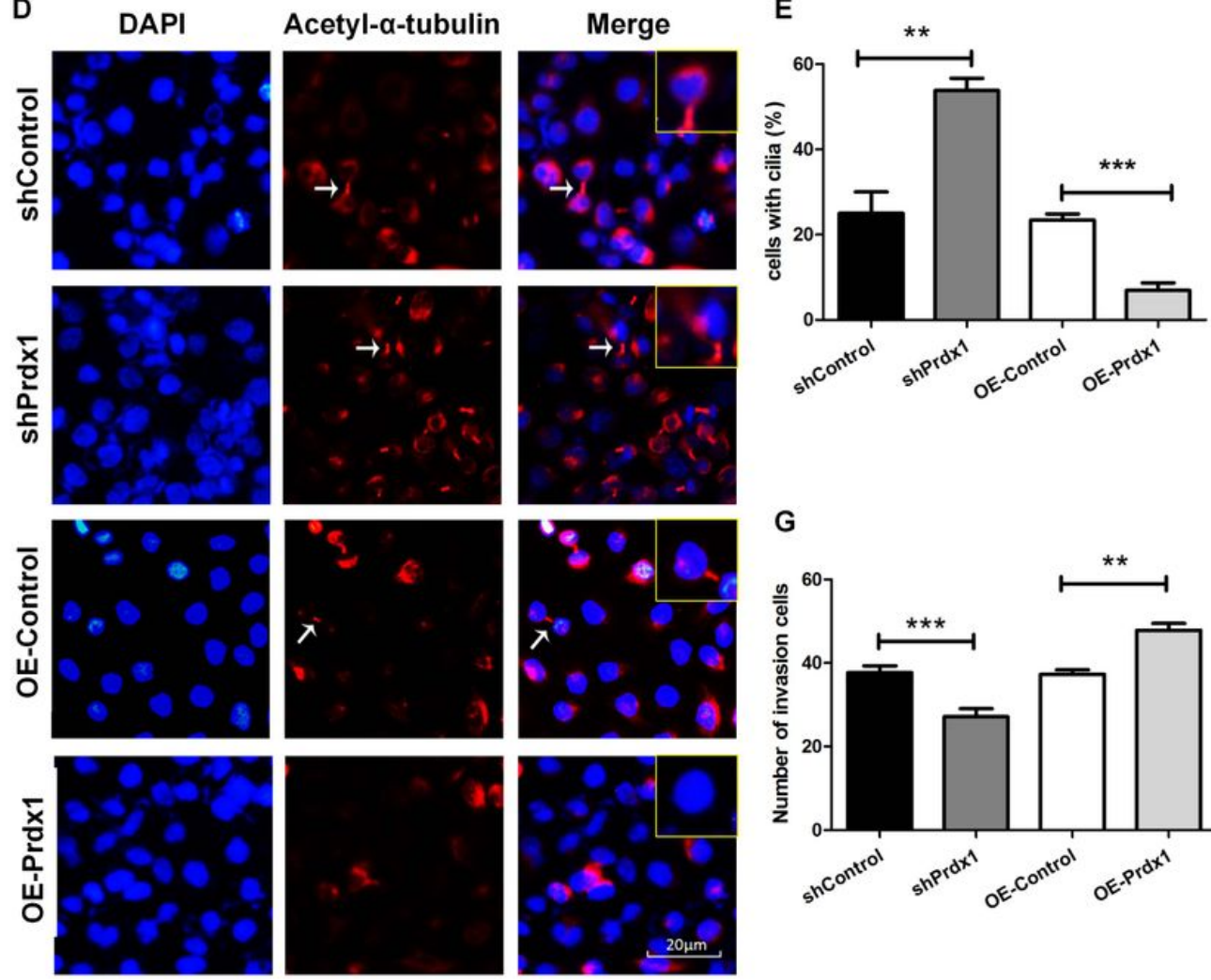

G

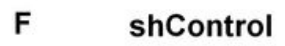

shPrdx1

OE-Control
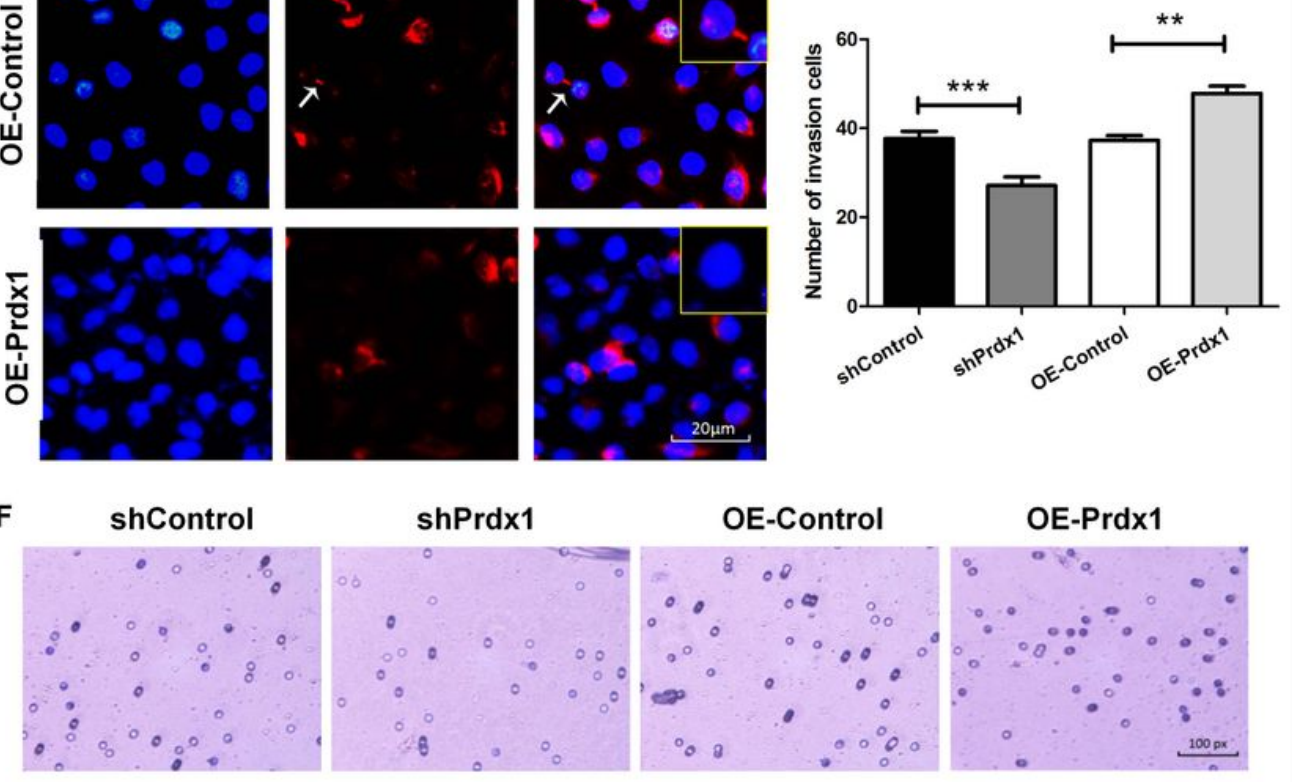

Figure 2

Inhibition of Prdx1 restored primary cilia and suppressed tumor invasion A Transfection efficiency of lentivirus in EC9706 cells. EC9706 cells were transfected with plasmids expressing shRNA or OE-RNA and green fluorescent protein. Green fluorescent protein was detected as a marker of transfection efficiency by fluorescence microscopy (100x). B Western blotting was used to analyze the expression of Prdx1 in each group. GAPDH served as a loading control. C Analysis of western blot signals using Image J. The relative protein levels are indicated as bars. All experiments were performed in triplicate and results are expressed as mean \pm SEM. D 
Immunofluorescence was used to detect the changes of the cilium marker protein (red: acetyl-a-tubulin, blue: DAPI, white arrows: cilia). E Number of cells with cilia (\%) in each group. F Transwell invasion experiment to detect the changes in cell invasion capacity. G Number of invasion cells in each group. ${ }^{\star} P<0.05,{ }^{\star *} P<0.01, * \star \star P$ $<0.001$.

A

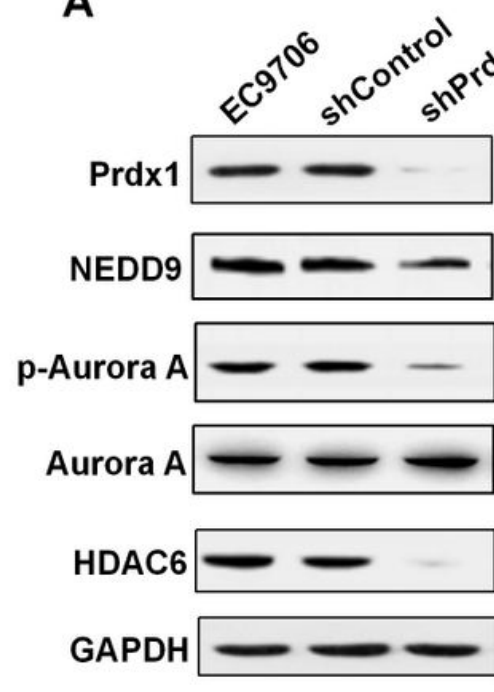

B

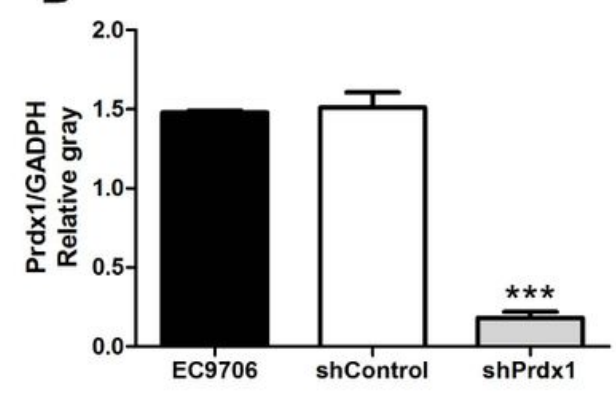

46 131
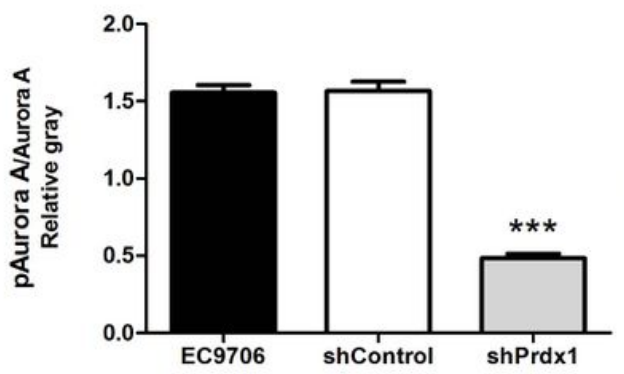
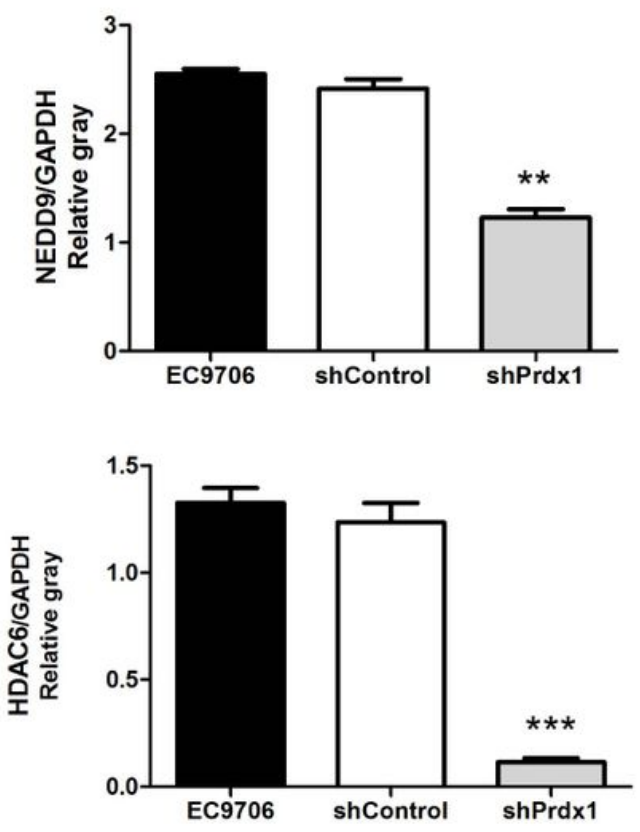

C

D
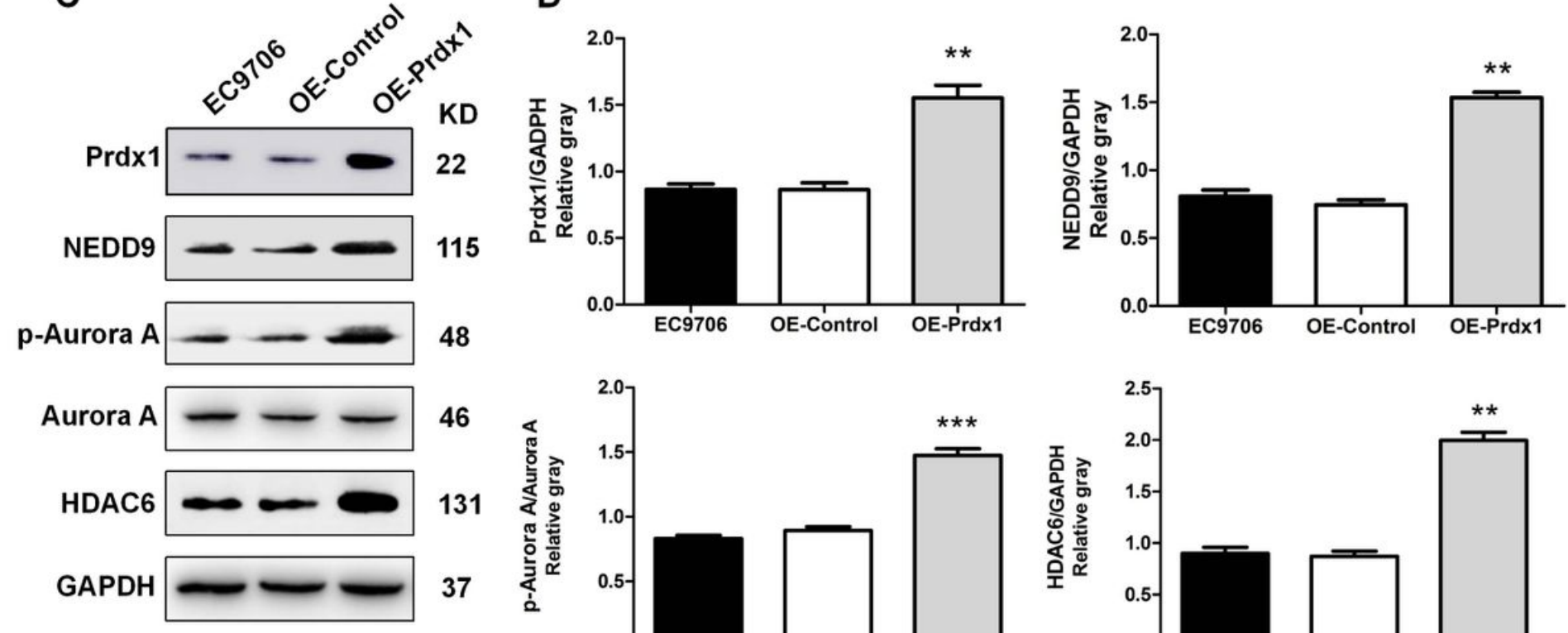

48

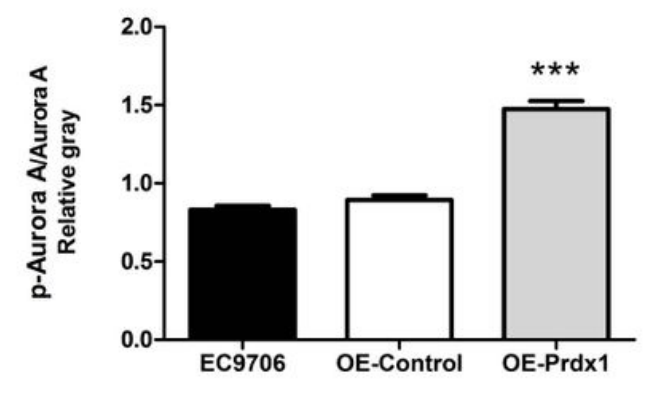

Figure 3

Prdx1 significantly regulated the expression of NEDD9-Aurora A-HDAC6 in EC9706 cells. A Western-blot was used to detect the expression levels of Prdx1, NEDD9, p-Aurora A, Aurora A, HDAC6, and GAPDH in cells of each group. B Analysis of western blot signals using Image J. GAPDH was used as a loading control. C Changes of the expression of Prdx1, NEDD9, p-Aurora A, Aurora A, HDAC6, GAPDH in cells of each group. D Analysis of western 
blot signals using Image J. GAPDH was used as a loading control. The relative protein levels are indicated as bars. All experiments were performed in triplicate and the results are expressed as mean $\pm S E M$. ${ }^{\star} P<0.05, \star \star P<$ $0.01, * \star * \mathrm{P}<0.001$.
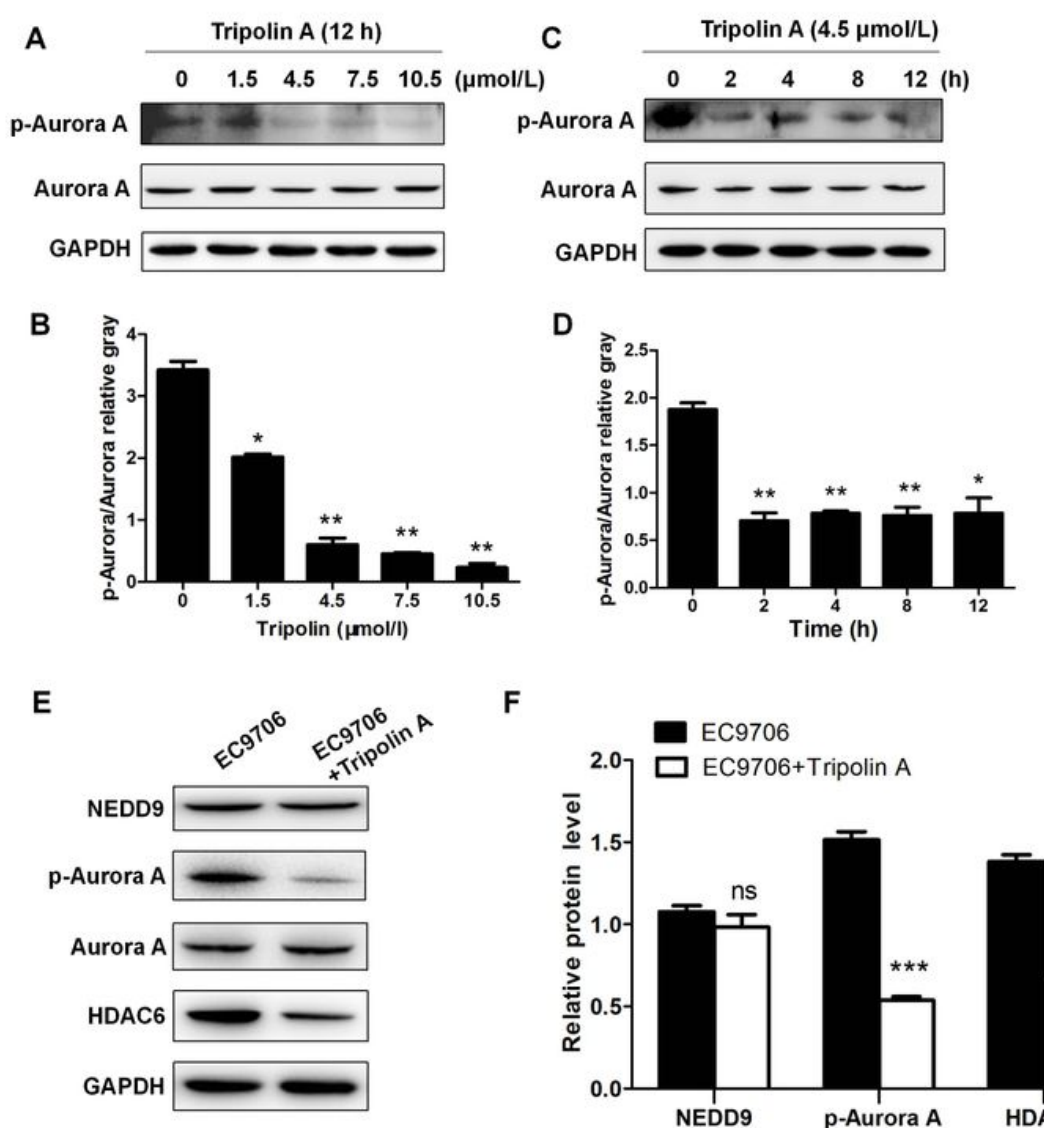

$\mathbf{F}$
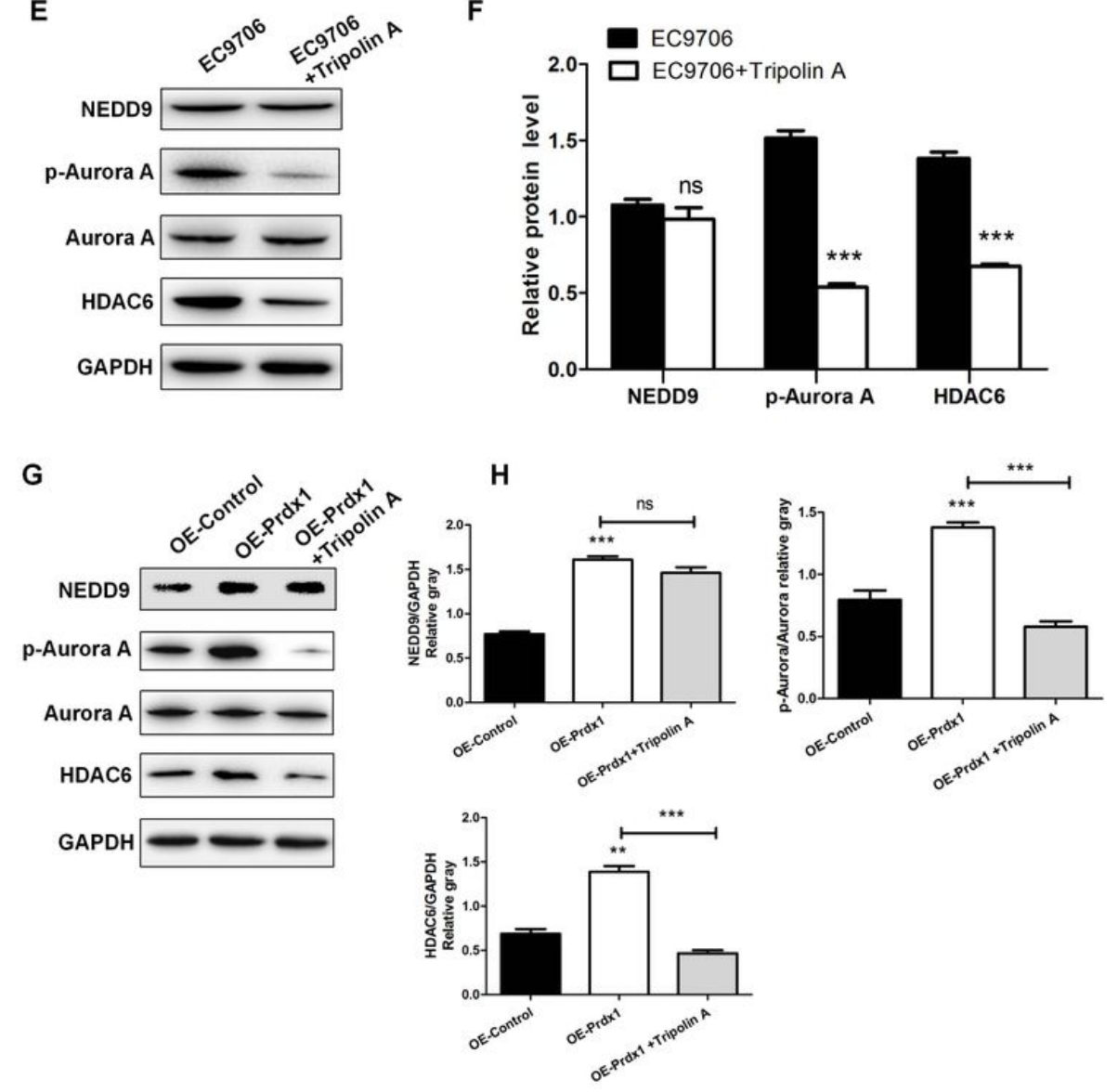

\section{Figure 4}

Tripolin A reversed the promotion effect of over-expressed Prdx1 on p-Aurora A and HDAC6. A Western-blot was used to detect changes of Aurora A expression in EC9706 cells treated with different concentrations $(0,1.5,4.5$, 7.5, and $10.5 \mu \mathrm{mol} / \mathrm{L}$ ) of Tripolin A. B Relative gray level for p-Aurora A/Aurora A in cells after treatment with different concentrations of Tripolin A. C Changes of p-Aurora A/Aurora A expression in EC9706 cells treated with $4.5 \mu \mathrm{mol} / \mathrm{L}$ Tripolin A for different lengths of time $(0,2,4,8$, and $12 \mathrm{~h})$. D Relative gray level of $p$-Aurora A/Aurora 
$A$ in cells after treatment with $4.5 \mu \mathrm{mol} / \mathrm{L}$ Tripolin A for different lengths of time. E The expression of NEDD9, pAurora A, Aurora A, and HDAC6 after EC9706 cells treated with $4.5 \mu \mathrm{mol} / \mathrm{L}$ Tripolin A for $2 \mathrm{~h}$. F Analysis of western blot signals using Image J. GAPDH was used as a loading control. G The expression of NEDD9, p-Aurora A, Aurora A, and HDAC6 in different treatment groups. The OE-Prdx1 group was EC9706 cells transfected with the OE-Prdx 1 lentivirus, and then treated with $4.5 \mu \mathrm{mol} / \mathrm{L}$ Tripolin A for $2 \mathrm{~h}$. H Relative expression of NEDD9, p-Aurora A and HDAC6 in cells of different groups. GAPDH was used as a loading control. ${ }^{\star} P<0.05$, ${ }^{\star *} \mathrm{P}<0.01$, ${ }^{\star \star *} \mathrm{P}<$ 0.001.

A

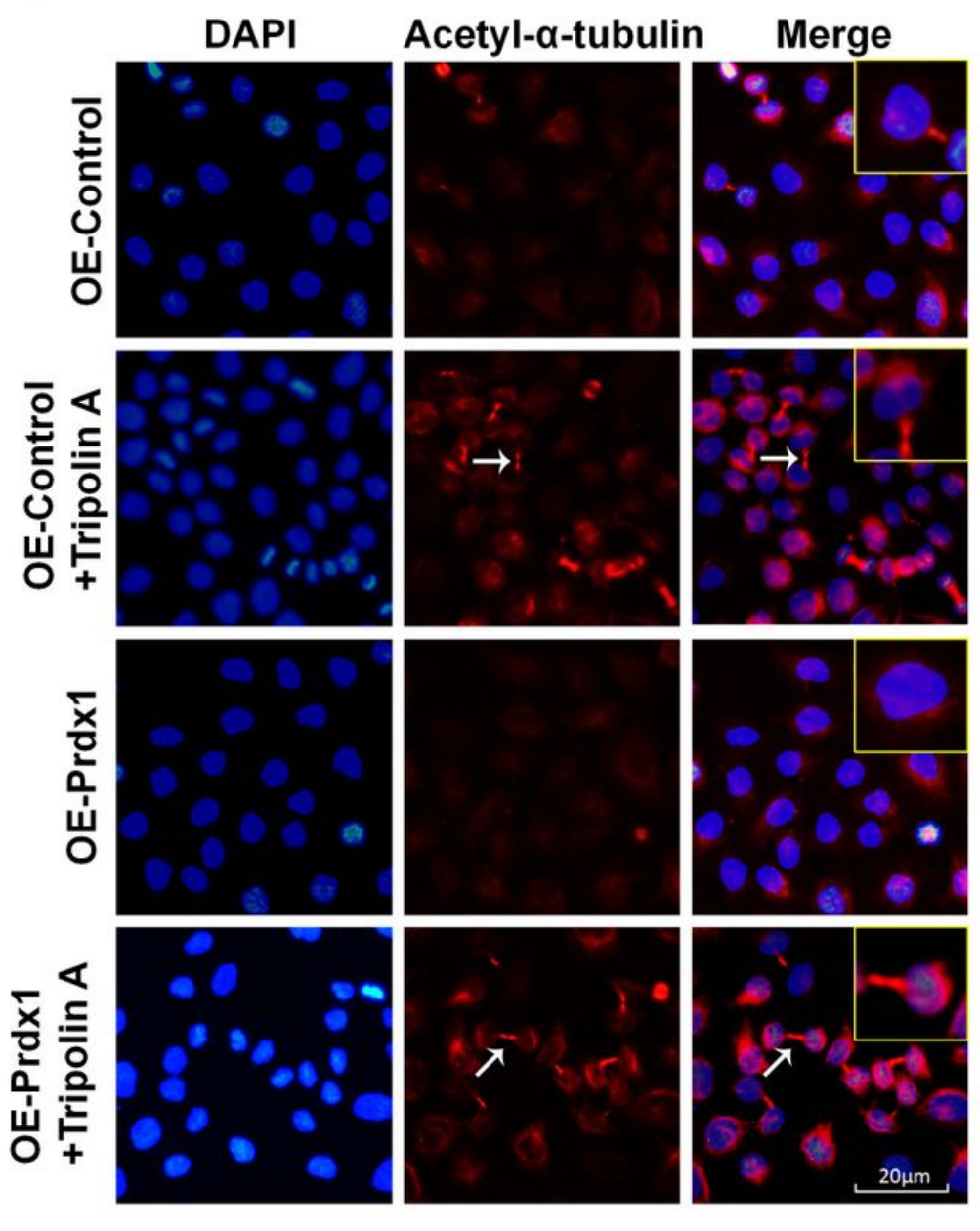

B
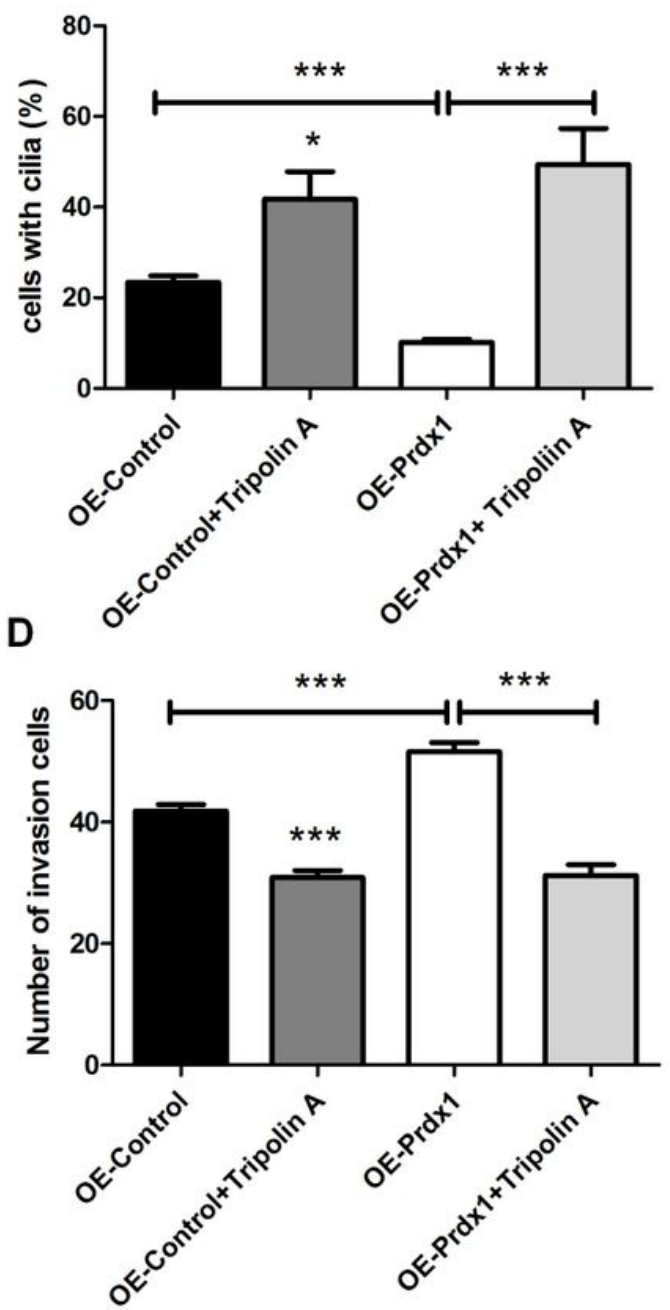

C OE-Control OE-Control+Tripolin A OE-Prdx1 OE-Prdx1+Tripolin A

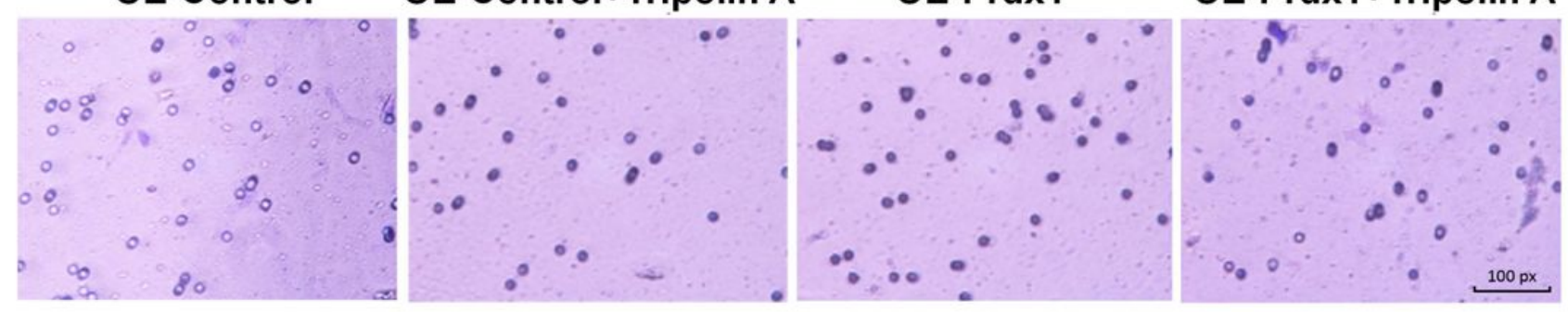

Figure 5 
Tripolin A reversed the promotion effect of over-expressed Prdx1 on cilium disaggregation and tumor invasion. A Immunofluorescence was used to detect changes of the cilium marker protein (red: acetyl-a-tubulin, blue: DAPI, white arrows: cilia) in different groups. B Number of cells with cilia (\%) in each group. C Transwell invasion experiment to measure cell invasion capacity in each group. D Number of invasion cells in each group. Data are presented as mean $\pm \mathrm{SEM},{ }^{*} \mathrm{P}<0.05,{ }^{*} \mathrm{P}<0.01,{ }^{* * * \mathrm{P}}<0.001$.

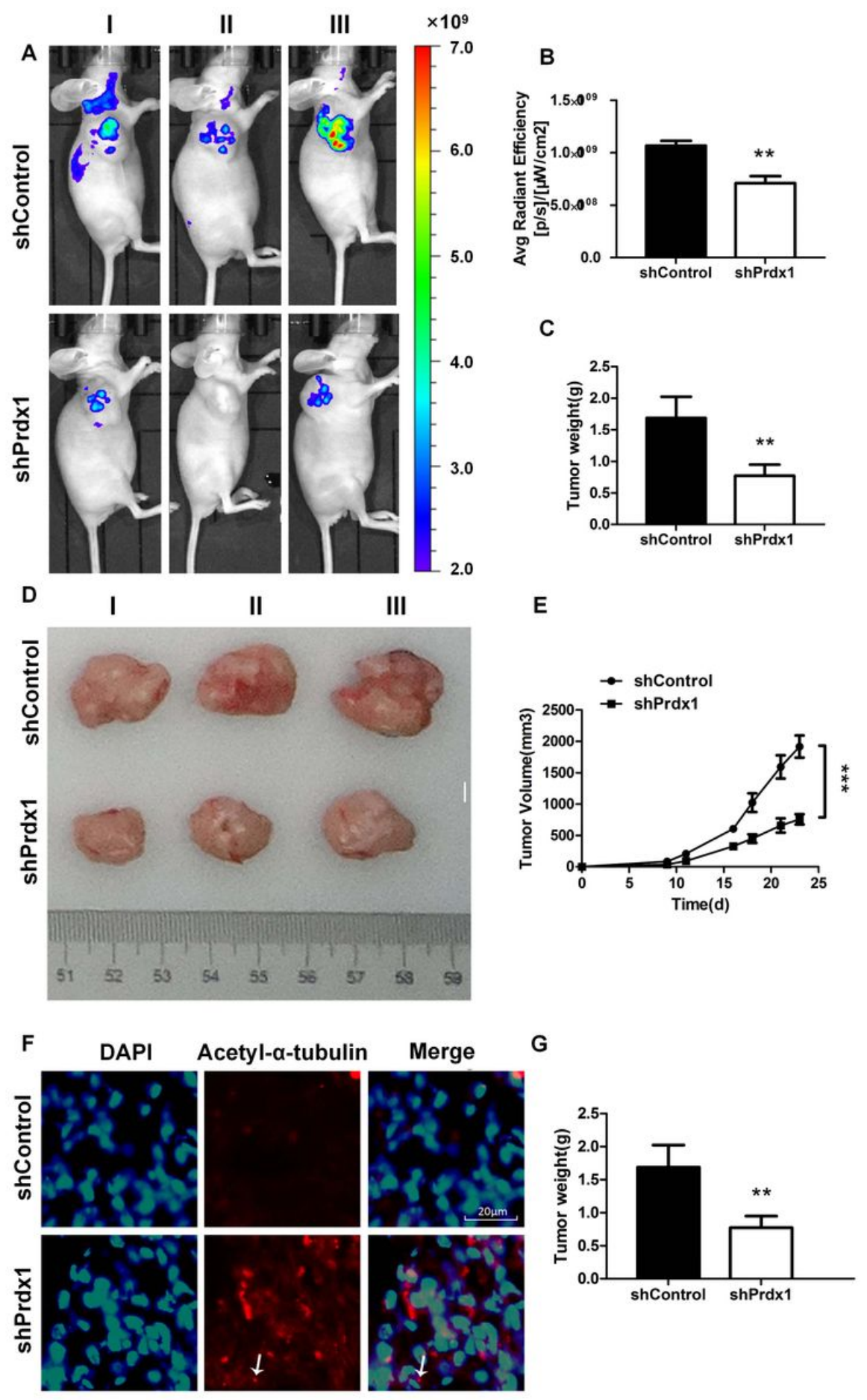

Figure 6

Inhibition of Prdx1 decreased tumorigenesis, reduced tumor volume and weight, and promoted cilia regeneration. A Live imaging was used to detect the tumorigenesis, and the radiant efficiency and distribution of luciferase luminescence were used as indicators of tumor formation ability and tumor invasive capacity, respectively. B The 
radiant efficiency of luciferase luminescence in each group. C Changes of tumor weight after inhibition of Prdx1. D-E Changes of tumor volume in each group. F Immunofluorescence assay to detect the cilium marker protein (red: acetyl-a-tubulin, blue: DAPI, white arrows: cilia) in tumor tissue of each group. G Changes in the number of cells with cilia (\%) in tumor tissue of each group. ${ }^{*} P<0.05,{ }^{*} P<0.01,{ }^{*} * *<0.001$.
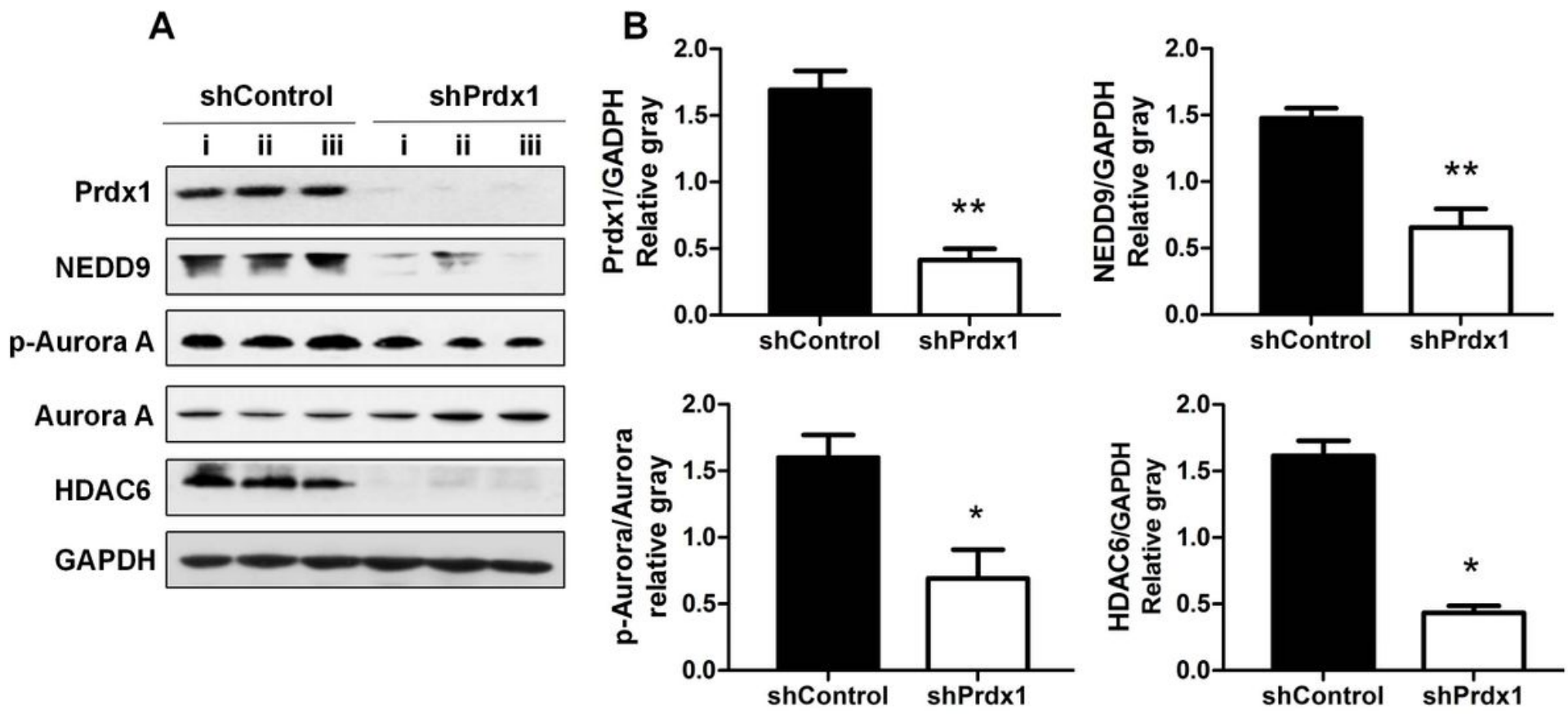

Figure 7

Decreased Prdx1 down-regulated the cilium disaggregation signal axis NEDD9-Aurora A-HDAC6 in tumor tissue. A Western-blot was used to detect changes of Prdx1, NEDD9, p-Aurora A, Aurora A, HDAC6, and GAPDH in tumor tissue of each group. B Analysis of western blot signals using Image J. GAPDH was used as a loading control. The relative protein levels are indicated as bars. All experiments were performed in triplicate and results are expressed as mean \pm SEM. ${ }^{*} \mathrm{P}<0.05,{ }^{*} \mathrm{P}<0.01,{ }^{*} * \mathrm{P}<0.001$.

\section{Supplementary Files}

This is a list of supplementary files associated with this preprint. Click to download.

- NC3RsARRIVEGuidelinesChecklist2014.docx

- TableS1.xlsx

- Figures1.tif

- Tables2.xls

- Tables3.xls

- figures2.tif

- SupplementaryFigureX.docx 